\title{
EFFECTS OF EXOGENOUS LACTOFERRIN ON PHENOTYPIC PROFILE AND INVASIVENESS OF HUMAN PROSTATE CANCER CELLS (DU-145 AND LNCaP) IN VITRO
}

\author{
T.V. Zadvornyi*, N.Y. Lukianova, T.V. Borikun, V.F. Chekhun \\ R.E. Kavetsky Institute of Experimental Pathology, Oncology and Radiobiology, \\ NAS of Ukraine, Kyiv 03022, Ukraine
}

\begin{abstract}
Aim: To investigate the biological effects of exogenous lactoferrin (LF) on phenotypic profile and invasiveness of human prostate cancer (PC) cells in vitro. Materials and Methods: Human PC cell lines (LNCaP, DU-145) were cultured with an exogenous $\mathrm{LF}$ at a dose corresponding to $\mathrm{IC}_{30}$. The expression levels of steroid hormone receptors (androgen receptor, estrogen receptor, progesterone receptor), Her2/neu, Ki-67, E- and N-cadherin, were monitored by immunohistochemical analysis. The levels of miRNAs were assessed using q-PCR. The invasive activity of the cells was examined in a standard invasion test. Results: Exogenous LF reduced expression of steroid hormone receptors (ER $\alpha$ and PR) and Ki-67 in both PC cell lines. The expression of E-cadherin increased significantly in LF-treated DU-145 cells. Also, we established the decrease in invasive activity upon LF treatment by $40 \%$ and $30 \%$ in DU-145 and LNCaP cells, respectively. In DU-145 cells, incubation with exogenous LF resulted in an increase in the expression of oncosuppressive (miR-133a and miR-200b) miRNAs. Conclusions: Exogenous LF causes the changes in phenotypic characteristics of PC cells and levels of oncogenic and oncosuppressive miRNAs involved in the regulation of key cellular processes. Key Words: prostate cancer, exogenous lactoferrin, DU145, LNCaP, miRNA.
\end{abstract}

Prostate cancer (PC) is one of the most common malignant neoplasms among men worldwide [1]. To date, novel methods of treatment have been developed and introduced into clinical practice; multicenter studies of the treatment of $\mathrm{PC}$ of various stages and types are being conducted. However, despite all the advances in the treatment, PC-related morbidity and mortality increase worldwide [1-3].

Due to the lack of early symptoms, PC is usually diagnosed at the late stages, when surgical intervention is impossible and conservative therapy is unsuccessful. D'Amico et al. [4] proposed a classification of PC that ascribes the patients with a level of prostate specific antigen $>20 \mathrm{ng} / \mathrm{ml}$, Gleason score of $8-10$, or a clinical stage $\geqslant T 2 \mathrm{c}$ to a high risk group or cancer with a high degree of malignancy. The validity of this classification recommended by the American Urological Association [5] has been proved in a number of studies $[6,7]$. Historically, the impossibility of effective treatment of highly malignant PC via a single radical prostatectomy has led to greater use of other therapeutic options, such as hormonal therapy as single modality or combined with radiotherapy [7].

Nowadays throughout the world, there is a search and development of approaches to reduce the degree of malignancy of PC by modifying the phenotype of tumor cells. It is considered promising to use the compounds with antioxidant properties, in particular, lactoferrin (LF). By its origin, LF is an iron-binding glycoprotein from the transferrin family, which carries iron to the cells and controls the level of "free" iron in the

Submitted: August 16, 2018.

*Correspondence: E-mail: tito132007@ukr.net Abbreviations used: AR - androgen receptor; ER - estrogen receptor; LF - lactoferrin; PC - prostate cancer; PR - progesterone receptor. blood and biological fluids [8, 9]. LF identified in blood plasma is one of the main components of almost all exocrine secretions of mammals such as saliva, bile, tears, pancreatic secretion, etc. [8-10]. LF is represented by three molecular isoforms - LF- $\alpha$, LF- $\beta$, LF- $\gamma$, two of which - LF- $\alpha$, LF- $\beta$ have ribonuclease activity [9]. LF molecule is highly resistant to proteoIytic degradation by trypsin-like enzymes $[10,11]$. This protein is well-known for its multiple biological functions such as antibacterial, antiviral, anti-tumor, anti-inflammatory, immunoregulatory properties, and also interacts with polyamines, heparin, DNA, and RNA [12]. In our previous studies in vitro, on the model of human breast cancer, it was found that LF disrupts the prooxidant/antioxidant balance by increasing the level of active forms of oxygen, "free iron" and the rate of NO generation. These disorders lead to blockage of the cell cycle in the G2/M phase and the death of malignant cells by apoptosis [13]. In vivo studies have shown that LF delays appearance of primary tumors and inhibits the growth rate of an experimental cervical cancer in mice $[14,15]$. However, in the available literature, there are only few reports devoted to the study of molecular biological effects of LF on the of human PC cell lines.

The aim of the work was to investigate the biological effects of exogenous LF on phenotypic profile and invasiveness of human PC cells in vitro.

\section{MATERIALS AND METHODS}

Cell lines. Two human PC cell lines DU145 and $\mathrm{LNCaP}$ were provided by the Bank of Cell Lines of Human and Animal Tissues at R.E. Kavetsky Institute of Experimental Pathology, Oncology and Radiobiology of the NAS of Ukraine. DU145 and LNCaP cells were grown in DMEM (Invitrogen, USA) supplemented with $10 \%$ fetal bovine serum (Gibco/Invitrogen, USA) 
at $37^{\circ} \mathrm{C}$ in a humidified atmosphere with $5 \% \mathrm{CO}_{2}$ and subcultured after reaching $80 \%$ of flask surface. In all experiments of this study, cells in log phase were subcultured for $24 \mathrm{~h}$ and the medium was replaced with fresh medium with or without reagents.

Lactoferrin. Recombinant human LF was kindly provided by the colleagues from the Institute of Physiology of the National Academy of Sciences of Belarus in the framework of the joint research project funded by the NAS of Ukraine and the NAS of Belarus "Molecular biological effects and mechanisms of lactoferrin influence on tumor cells in in vitro and in vivo systems" Contract No. 07-04-15 [16]. LF was diluted in PBS and added directly to the culture medium at a dose corresponding to $\mathrm{IC}_{30}$. Cells were cultured with LF during $48 \mathrm{~h}$.

Immunocytochemical methods. Cells for immunocytochemical studies were grown on glass cover slips, fixed in cooled mixture of methanol:acetone (1:1) at $-20^{\circ} \mathrm{C}$ for $120 \mathrm{~min}$, washed in PBS and incubated with $1 \%$ BSA for $20 \mathrm{~min}$. The following primary monoclonal antibodies were used: anti-androgen receptor (Thermo Scientific, USA); anti-estrogene a receptor (Thermo Scientific, USA); anti-estrogene $\beta$ receptor (Thermo Scientific, USA); anti-progesterone receptor (Thermo Scientific, USA); anti-Ki-67 (Dako Cytomation, Denmark); anti-E-cadherin (Thermo Scientific, USA), anti-EerbB2 (Thermo Scientific, USA); anti-CD325 (N-Cadherin) (Dako Cytomation, Denmark). The antibodies diluted in the blocking buffer were added to the cell specimens for one hour followed by incubation with Ultra Vision LP Detection System (Lab Vision, Thermo Scientific). After the washing, the immune reaction was visualized using DAB Quanto (Thermo Scientific). When immunocytochemical reactions were completed, the cells were stained with hematoxylin by Mayer for $10-15 \mathrm{~s}$ and placed in Faramount Aqueous Mounting Medium (Dako Cytomation, Denmark). The results were evaluated in 3 visual fields by light microscopy $(\times 100$, oil immersion) using the classical $\mathrm{H}$-Score method:

$$
S=1 \cdot N_{1+}+2 \cdot N_{2+}+3 \cdot N_{3+}
$$

where $\mathrm{S}$ is «H-Score» index; $\mathrm{N}_{1+}, \mathrm{N}_{2+}$ and $\mathrm{N}_{3+}$ are numbers of cells with low, medium or high levels of marker expression. It should be noted that in previous studies we have identified biomolecular markers that characterize the metastatic potential and invasive activity of PC cells of abovementioned lines [17].

Invasive activity was investigated using a standard method with the matrigel membranes (BD BioCoat ${ }^{\mathrm{TM}}$

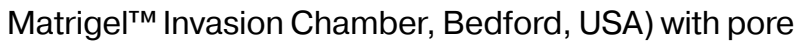
sizes of 8 microns, according to manufacturer's recommendations. In the upper part of the membrane, the cell suspension was placed in a concentration of $5 \cdot 10^{4}$ cells/well in culture medium without bovine serum. In the lower part, the standard culture medium supplemented with $10 \%$ fetal bovine serum was introduced. The cells were then incubated under standard conditions at the temperature of $37^{\circ} \mathrm{C}$ in humidified atmosphere with $5 \% \mathrm{CO}_{2}$ during 48 hours. The membranes were then fixed with methanol followed by stain- ing with crystal violet $B$ and the cells invading through membrane were counted on the outside of membrane using light microscopy ( $\times 100$, oil immersion).

Total RNA isolation. Total RNA extraction was performed using Ribozol RNA Isolation Kit (Amplisens, Russia). Concentration of RNA was measured using NanoDrop 2000c Spectrophotometer (Thermo Scientific, USA). The purity of isolated RNA was controlled by OD ratio at $260 / 280 \mathrm{~nm}$. RNA was dissolved in TE buffer and stored at $-20^{\circ} \mathrm{C}$. Single-stranded cDNA was synthesized from $100 \mathrm{ng}$ of total RNA, using TaqMan ${ }^{\oplus}$ MicroRNA Kit (Applied Biosystems, USA) for reverse transcription.

Real-time quantitative reverse transcription polymerase chain reaction ( $q R T$-PCR). Preparation of reverse transcription reaction mix was performed according to manufacturer's protocol. Reverse transcription was performed at a "Tertsik" (DNA Tehnologiya, Russian Federation) thermal cycler. qRTPCR was performed on Applied Biosystems 7900HT Fast Real-Time PCR System using TaqMan ${ }^{\circledR}$ MicroRNA primers (Applied Biosystems, USA) and Maxima SYBR Green/ROX qPCR Master Mix (2X) (Thermo Scientific, USA) by manufacturer's protocol. Small nucleolar RNA RNU48 was used as an endogenous control for normalization of miRNA expression. Relative expression of the studied miRNAs was identified by comparative $\mathrm{Ct}$ method. Experiments were performed in triplicates for each line, and PCR was performed three times for each sample. Expression differences between the studied miRNA levels relative to control was calculated by the formula:

Fold change $=2^{-\Delta \Delta C t}$,

where $\Delta \mathrm{Ct}$ (target - control) is equal to the difference between threshold cycles for miRNA (target) and the threshold cycle for RNU48 (control) $\Delta \mathrm{Ct}$ (target - control $)=\mathrm{Ct}$ target $-\mathrm{Ct}$ control). $\Delta \Delta \mathrm{Ct}=\Delta \mathrm{Ct}$ (experiment) $-\Delta \mathrm{Ct}$ (control).

Statistical analysis was performed using STATISTICA 6.0 software (StatSoft Inc., USA). All data were obtained in triplicates. The values were expressed as means \pm standard deviation (SD). Student's $t$-test was used to evaluate the significance of the differences between groups. A value of $p<0.05$ was accepted as statistically significant.

\section{RESULTS}

Phenotypic characteristics of DU-145 and LNCaP cells. We have found that DU-145 and LNCaP cell lines were characterized by the presence of steroid hormones receptors and HER2/neu (Table 1). The high level of androgen receptor (AR) expression was established in DU-145 cells $(282.0 \pm 14.0$ points by the $\mathrm{H}$-Score) and in LNCaP (270.0 \pm 8.0 points by the $\mathrm{H}$-Score). In the cells of both studied lines, high expression level of estrogen receptor (ER) $\beta$, low level of ERa and medium level of progesterone receptor (PR) were detected. No significant differences were found between the expression of HER2/neu in the DU-145 and LNCaP lines $(84.0 \pm 11.3$ and $94.0 \pm 4.0$ points by $\mathrm{H}$-Score, respectively). 
Table 1. Molecular profile of human PC cells of DU-145 and LNCaP lines

\begin{tabular}{|c|c|c|}
\hline & DU-145 & LNCaP \\
\hline \multicolumn{3}{|c|}{ Receptor status } \\
\hline$\overline{\mathrm{AR}}$ & $282.0 \pm 14.0$ & $270.0 \pm 8.0$ \\
\hline ERa & $80.0 \pm 13.0$ & $98.0 \pm 12.0$ \\
\hline ER $\beta$ & $276.0 \pm 9.3$ & $280.0 \pm 10.6$ \\
\hline PR & $117.0 \pm 18.0$ & $150.0 \pm 17.6$ \\
\hline HER2/neu & $84.0 \pm 11.3$ & $94.0 \pm 4.0$ \\
\hline \multicolumn{3}{|c|}{ Markers of intercellular adhesion } \\
\hline E-cadherin & $35.0 \pm 6.6$ & $3.0 \pm 1.0$ \\
\hline $\mathrm{N}$-cadherin & $175.0 \pm 12.7^{\star}$ & $247.0 \pm 11.6$ \\
\hline \multicolumn{3}{|c|}{ Markers of proliferative activity } \\
\hline Ki-67 & $265.0 \pm 20.5^{*}$ & $174.0 \pm 24.6$ \\
\hline \multicolumn{3}{|c|}{ Invasive activity, $\times 10^{3}$ cells } \\
\hline & $0.387 \pm 0.005^{\star}$ & $0.076 \pm 0.007$ \\
\hline
\end{tabular}

Note: ${ }^{\star} p<0.05$ compared with LNCaP cells.

The study of adhesive properties demonstrated a low expression of $\mathrm{E}$-cadherin in the cells of the studied lines (Table 1), while the expression of $\mathrm{N}$-cadherin in DU-145 cells was significantly lower than that in the LNCaP cells $(175 \pm 12.7$ and $247 \pm 11.6$ points by $\mathrm{H}$-Score, respectively).

DU- 145 cells also showed significantly higher rates of proliferative (Ki-67 - 265.0 \pm 20.5 points by the $\mathrm{H}$-Score $)$ and invasive activity $\left(0.387 \cdot 10^{3}\right.$ cells $)$ compared to LNCaP cells in which the level Ki-67 was $174.0 \pm 24.6$ points by the $\mathrm{H}$-Score, and the invasive activity value was $0.076 \cdot 10^{3}$ cells (Table 1 ).

miRNA profile in DU-145 and LNCaP cells. Using the resource http://mirbase.org, we have chosen a panel of micro-RNAs involved in the oncogenesis of human $\mathrm{PC}$ and in regulation of the expression of steroid hormones receptors (miRNA-205 and miRNA-155), intercellular adhesion proteins (miRNA-200b), proliferative (miRNA-133a) and invasive (miRNA-205) activity $[18,19]$. According to our data (Fig. 1), the level of miRNA-205 was significantly higher in cells of the DU-145 line compared to the LNCaP line ( $0.250 \pm 0.010$ and $0.208 \pm 0.011$ a.u., respectively). It was found that the levels of miRNA-155 in the studied cell lines did not differ significantly.

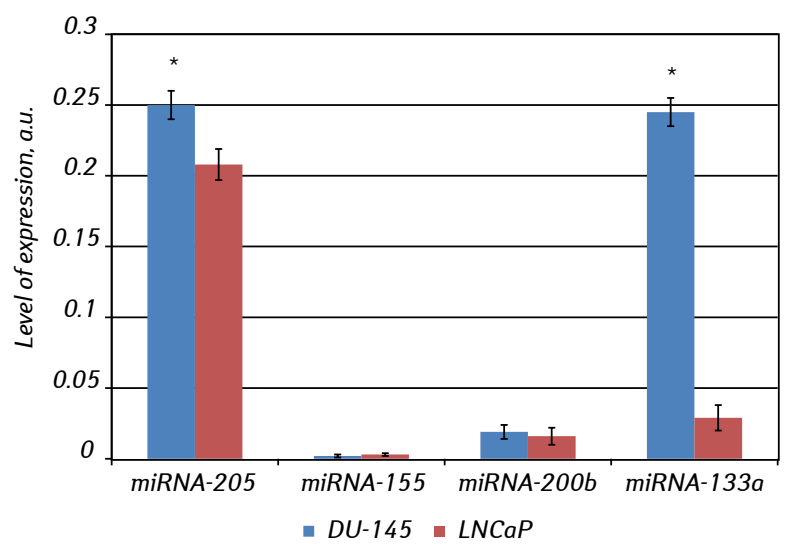

Fig. 1. miRNA expression in human PC cell lines. ${ }^{*} p<0.05$ compared with LNCaP cells

The level of miRNA-133a was significantly higher in DU-145 cells $(0.245 \pm 0.010$ a.u. $)$ compared to the LNCaP line for which this index was $0.029 \pm 0.009$ a.u. There were no differences in the levels of miRNA-200b in these cells (Fig. 1).

Effect of exogenous $L F$ on the expression level of the miRNA in the human PC cell lines. At the next stage of our study we have analyzed the effect of exogenous LF on the level of miRNAs expression in the cells of human PC cell lines. It was found that under the action of exogenous LF in both cell lines there was an increase in the expression of miRNA-205 and miRNA-155 (Fig. 2).

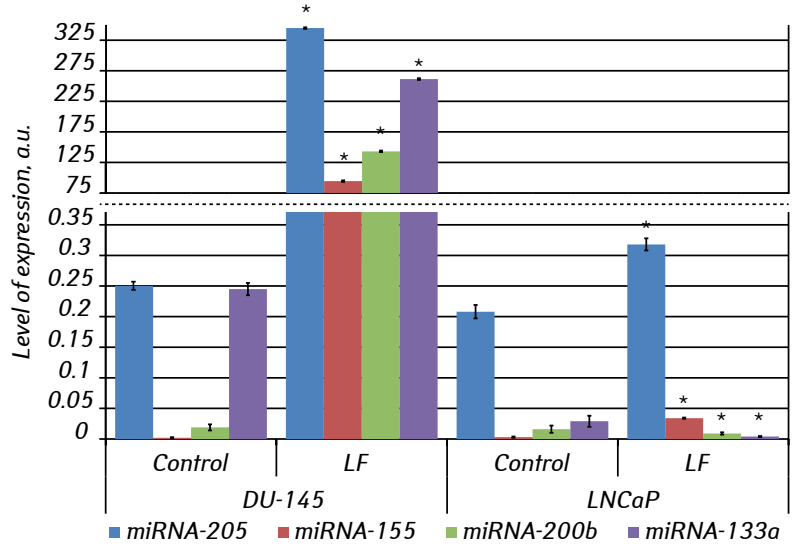

Fig. 2. The effect of exogenous LF on the level of miRNAs expression in the cells of human PC cell lines. ${ }^{*} p<0.05$ compared with the control

The most significant changes in the expression of miRNA-205 expression were detected in DU-145 cells, in particular, its level increased up to $344.89 \pm 1.34$ a.u. In LNCaP cells, the level of miRNA-205 increased up to $0.318 \pm 0.010$ a.u. A similar pattern was also established for miRNA-155, the level of expression of which under the action of LF increased to $194.35 \pm 1.25$ a.u. and $0.034 \pm 0.001$ a.u. in the DU-145 and LNCaP cell lines, respectively.

Cultivation of the DU-145 cells with exogenous LF resulted in a significant increase in the expression of miR-200b (up to $143.01 \pm 1.28$ a.u.) and miRNA-133a (up to $261.38 \pm 1.418$ a.u.). In the LNCaP cells, the change of expression of these miRNAs was reversed, namely, decreased to $0.009 \pm 0.002$ a.u. and $0.004 \pm 0.001$ a.u., respectively.

Effect of exogenous LF on phenotypic characteristics of human PC cell lines. Next, we have studied the modifying effect of exogenous LF on the molecular profile of human PC cells. Taking into account the importance of steroid hormones receptors in carcinogenesis [20,21], we have studied the effect of exogenous LF on their expression in the cells of the $\mathrm{PC}$ lines.

It was established that cultivation of both cell lines with exogenous LF did not lead to a significant change in AR level (Fig. 2). It was found that under the action of LF there was a decrease (almost double) of the expression level of ERa (up to $47.3 \pm 7.3$ points by H-Score for DU-145 cells and $55.0 \pm 10.0$ points by $\mathrm{H}$-Score for LNCaP cells). Similar changes were also observed for PR, whose expression level after cultivation in the presence of $L F$ was $60.0 \pm 11.3$ and $78.0 \pm 13.0$ points by $\mathrm{H}$-Score in DU-145 and LNCaP cells, respectively (Fig. 3, 4).

As can be seen from the data shown in Fig. 5, the cultivation of DU- 145 cells with exogenous LF resulted in an increase in the expression of E-cadherin 


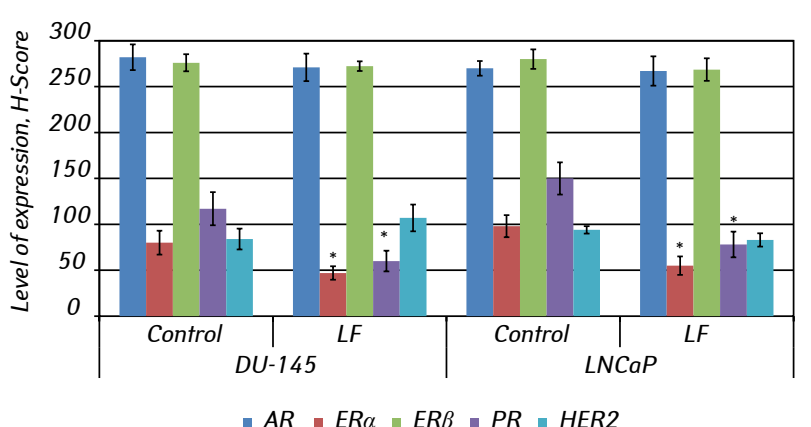

Fig. 3. The level of expression of steroid hormones receptors in the cells of human PC cell lines under the influence of exogenous LF. ${ }^{*} p<0.05$ compared with control

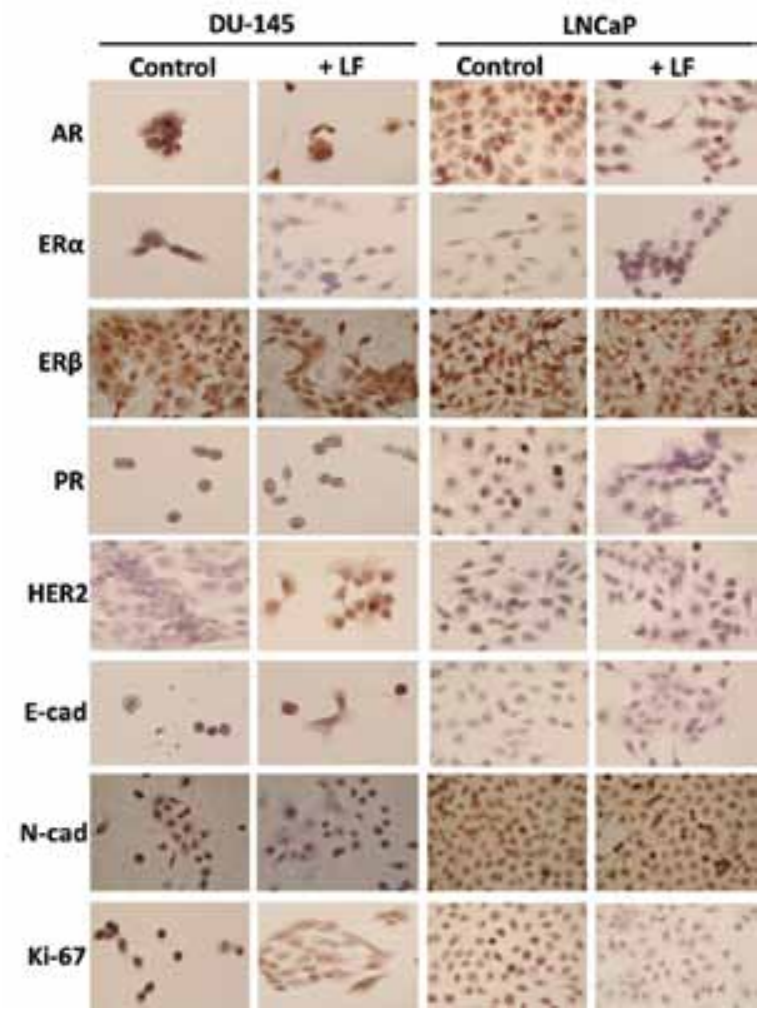

Fig. 4. The effect of exogenous LF on the molecular profile of human PC cells

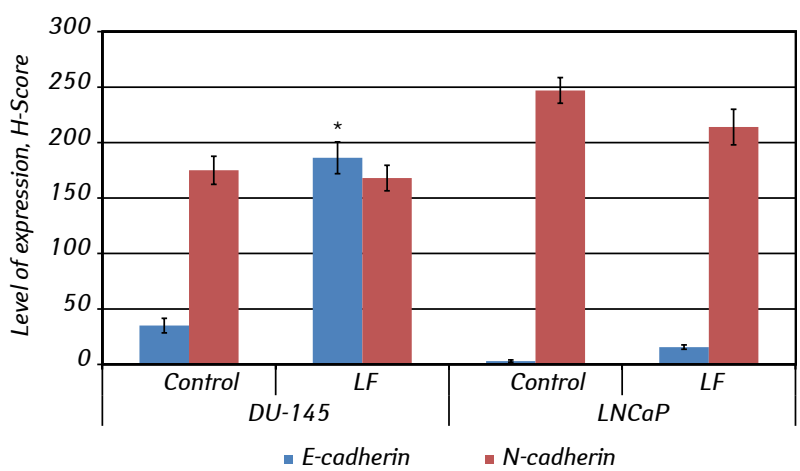

Fig. 5. Effect of exogenous LF on the expression level of intercellular adhesion molecules in human PC cells. ${ }^{*} p<0.05$ compared with the control

by 5.3 times, up to $186.3 \pm 13.0$ points by H-Score. There was no change in the level of another molecule of intercellular adhesion, $\mathrm{N}$-cadherin, whose expression rates were $175.0 \pm 14.3$ and $214.0 \pm 16.0$ points by $\mathrm{H}$-Score in DU-145 and LNCaP cells, respectively.
Exogenous LF decreases the indices of proliferative and invasive activity of the cells of both investigated lines (Table 2). In particular, the level of Ki-67 expression under the influence of exogenous LF decreased by $41 \%$ and $50 \%$ in DU-145 and LNCaP cell lines, respectively. Similar changes were observed with the indices of invasive activity, which decreased by almost $40 \%$ and $30 \%$ in DU-145 and LNCaP cell lines, respectively.

Table 2. Influence of exogenous LF on indices of proliferative and invasive activity of human PC cells

\begin{tabular}{|c|c|c|c|}
\hline \multicolumn{2}{|c|}{ Cell line } & Ki-67, H-score points & Invasive activity, $\cdot 10^{3}$ cells \\
\hline$\overline{\mathrm{DU}-14 !}$ & $\begin{array}{l}\text { Control } \\
\text { LF }\end{array}$ & $\begin{array}{l}265.0 \\
156.0\end{array}$ & $\begin{array}{c}0.387 \pm 0.005 \\
0.234 \pm 0.002^{*}\end{array}$ \\
\hline LNCaP & $\begin{array}{l}\text { Control } \\
\text { LF }\end{array}$ & $\begin{array}{l}174.0 \pm 24.6 \\
87.3 \pm 15.7^{\star}\end{array}$ & $\begin{array}{c}0.076 \pm 0.007 \\
0.054 \pm 0.004^{*}\end{array}$ \\
\hline
\end{tabular}

Note: ${ }^{\star} p<0.05$ compared with the control.

\section{DISCUSSION}

We have analyzed the effects of exogenous LF on phenotypic profile and invasiveness in two human PC cell lines. DU- 145 and LNCaP cells were both derived from PC metastases. DU-145 cells - from brain metastases of aggressive PC [22] and LNCaP cells - from the metastases in the supraclavicular lymph node [23]. DU- 145 cells are hormone-refractory and do not express a prostate-specific antigen [22, 24, 25]. The xenografts of DU- 145 cells exhibit moderate potential for metastasizing [26]. Hormone-sensitive LNCaP cells contain high-affinity cytoplasmic and nuclear androgen receptors and estrogen receptors in cytoplasm. Usually, it is used for the study as androgen-sensitive prostate adenocarcinoma [27, 28].

Insensitivity to antiandrogen therapy of DU-145 cell line may be explained by the expression of alternative splice-variant of AR - AR3, which provides ablationindependent growth of PCA cells. Also, AR3 can play an important role in this type of growth by regulation of unique set of genes, including AKT1, which are not controlled by prototype AR [29].

We have shown that DU-145 and LNCaP cell lines have similar expression profile of steroid hormones receptors, and HER2/neu. Nevertheless, such two lines differ in E-cadherin and Ki-67 expression and differ markedly by invasive activity assayed in vitro that may be suggestive of their putative differences in the degree of malignancy. Taking into account the importance of the epigenetic component in acquiring the degree of malignancy, we analyzed the levels of the miRNAs in human PC cells. DU- 145 cells are characterized by higher levels of oncogenic miRNA-205 and miRNA-155. In LNCaP cells, significantly higher level of oncosuppressive miRNA-133a was detected. So, we have established that human PC cell lines under study differ in their adhesive and invasive properties, as well as the level of proliferative activity. The different phenotypic profiles of DU-145 and $\mathrm{LNCaP}$ cell lines may suggest the difference in malignant potential of these cells.

Exogenous LF induces similar shifts in the phenotypic profile of both cell lines decreasing ERa and PR expression and increasing expression of E-cadherin with different magnitude of the effects in each cell line. 
In both cell lines, exogenous LF also increases the expression of miRNA-205 and miRNA-155, which are involved in regulating the expression of steroid hormones receptors, while the levels of miR-133a and miR-200b miRNAs were increased only in LF-treated DU- 145 cells. According to the literature [30], miRNA-155 regulates the synthesis of such proinflammatory cytokines as IL- 1 and IL- 6 resulting in a decrease in the expression of ER $a$ and PR, confirmed by our own studies. The results obtained are important given that estrogens can affect the carcinogenesis in the prostate through ERa-mediated signaling, being the part of a group of socalled hormonal nuclear receptors, and can interact directly with certain domains of genomic DNA by activating/blocking the transcription of target genes [20]. According to clinical observations, a high level of ERa is detected in the hormone-refractory PC, both in the primary lesion and in metastases. It should be noted that similar data were obtained by $\mathrm{Ha}$ et al. who found that cultivation of cells with exogenous LF is associated with decreased expression of ERa and PR [31].

ERa is also one of the key determinants of cell cycle regulation, acting by inhibiting p53/p21 and increasing the expression of PCNA and Ki-67. In view of this, reduction of ERa expression, which was observed after culturing cells with exogenous LF, may result in the inhibition of proliferation [32]. We have shown that the treatment of DU- 145 cells with LF leads to an increase in the level of miRNA-133a, an inhibitor of proliferative activity.
Another mechanism for regulating proliferation, according to Mariller et al. [33], can be the direct binding of LF to the promoter of the Skp1 gene with further activation of its expression. Exogenous LF has been shown to reduce the expression of cyclins D1 and/ or D4 that take part in the cell transition to the S-phase. The studies have shown that the cause of growth retardation may be the blocking of the cell cycle in the G0/ G1 phase. A similar effect of LF on the cell cycle was also demonstrated on the model of the nasopharyngeal carcinoma. In this case, the expression of cyclin D1 decreased, while the expression of p21 and p27 increased [32-34].

Exogenous LF also causes the increase in the expression of miRNA-200b involved in regulating expression of the intercellular adhesion molecule E-cadherin. The increase of $\mathrm{E}$-cadherin expression after cultivation of cells with exogenous LF can also occur due to the changes in ERa/ER $\beta$ ratio [35]. As a result, the invasive activity of the cells decreases. It is worth noting that for the numerous types of malignant tumors, including PC, E-cadherin expression correlates with more favorable prognosis. It is believed that the decrease or loss of E-cadherin expression correlates with invasiveness of the tumor, the formation of distant metastases, and unfavorable clinical prognosis [36, 37].

In conclusion, we have demonstrated that exogenous LF triggers the changes in phenotypic characteristics of PC cells and the expression of oncogenic

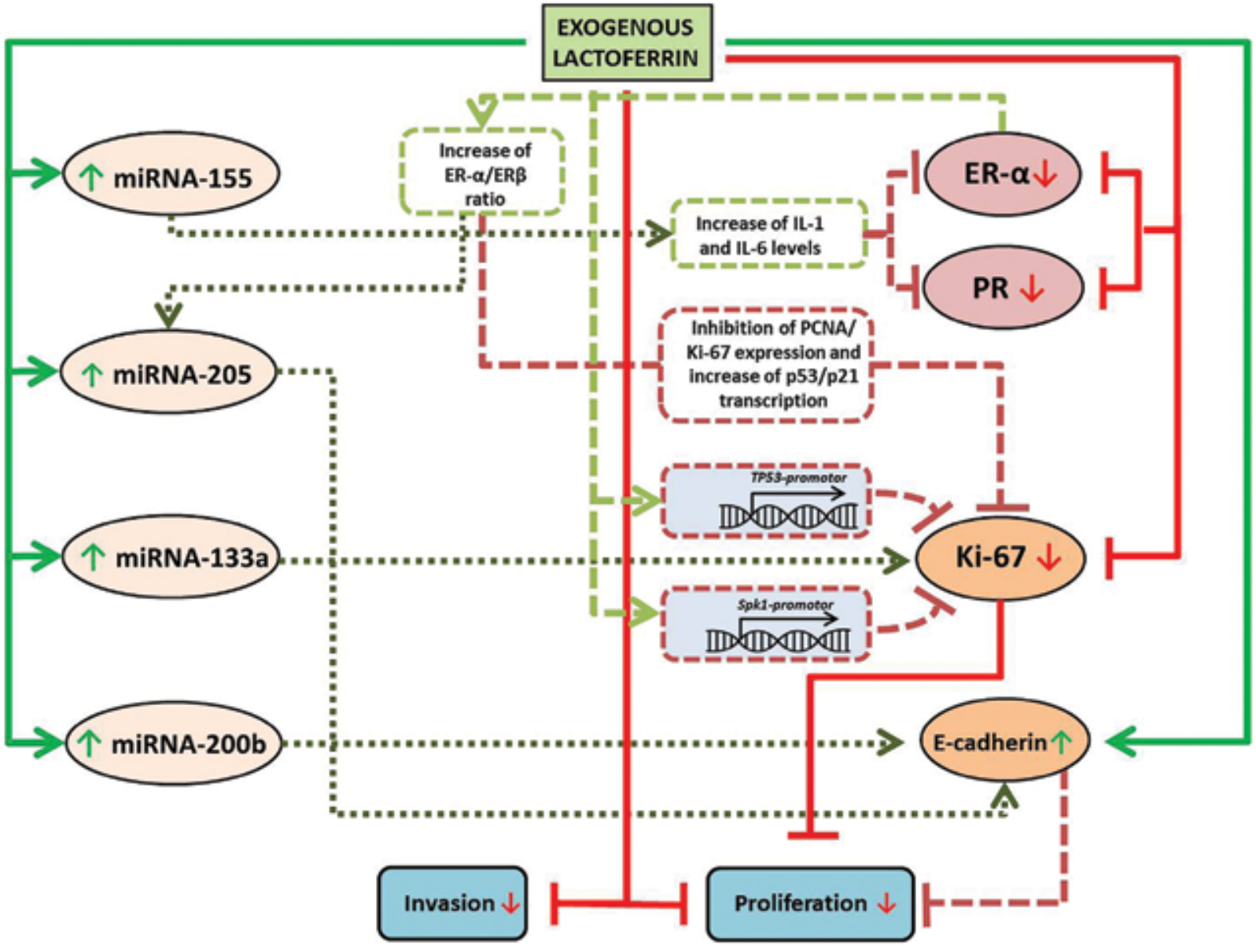

Fig. 6. Mechanism of action of exogenous LF on human PC cells 
and oncosuppressive miRNAs involved in the regulation of key cellular processes. Several putative targets of LF in PC cells are summarized in Fig. 6. Undoubtedly, further studies will ascertain the mechanisms of action of exogenous LF on human PC cells.

\section{REFERENCES}

1. Siegel RL, Miller KD, Jemal A. Cancer Statistics, 2016. CA Cancer J Clin 2016; 66: 7-30.

2. Aly A, Mullins CD, Hussain A. Understanding heterogeneity of treatment effect in prostate cancer. Curr Opin Oncol 2015; 27: 209-16.

3. Sfanos KS, De Marzo AM. Prostate cancer and inflammation: the evidence Histopathology 2012; 60: 199-215.

4. D'Amico AV, Whittington R, Malkowicz BS, et al. Biochemical outcome after radical prostatectomy, external beam radiation therapy, or interstitial radiation therapy for clinically localized prostate cancer. JAMA 1998; 280: 969-74.

5. Thompson I, Thrasher JB, Aus G, et al. Guideline for the management of clinically localized prostate cancer: 2007 update. J Urol 2007; 177: 2106-31.

6. D'Amico AV, Whittington R, Malkowicz SB, et al. Predicting prostate specific antigen outcome preoperatively in the prostate specific antigen era. J Urol 2001; 166: 2185-8.

7. Veliyev EI, Sokolov EA, Loran OB, et al. High-risk prostate cancer: the oncological efficiency of radical prostatectomy. Cancer Urology 2014; 10: 53-7 (in Russian).

8. Hwang SM, Chung IY, Jo JH, et al. Comparison of proliferative effect of human lactoferrin and its proteolytic peptide on normal and transformed epithelial cells. Appl Biochem Biotechnol 2016; 178: 44-57.

9. Kanwar JR, Roy K, Patel Y, et al. Multifunctional iron bound lactoferrin and nanomedicinal approaches to enhance its bioactive functions. Molecules 2015; 20: 9703-31.

10. Karav S, German JB, Rouquié C, et al. Studying lactoferrin N-glycosylation. Int J Mol Sci 2017; 18: pii. E870.

11. Shankaranarayanan JS, Kanwar JR, Al-Juhaishi AJA, et al. Doxorubicin conjugated to immunomodulatory anticancer lactoferrin displays improved cytotoxicity overcoming prostate cancer chemoresistance and inhibits tumour development in TRAMP mice. Sci Rep 2016; 6: 32062.

12. Farziyan MA, MoradianF, Rafiei A. Anticancer effect of bovine lactoferrin on human esophagus cancer cell line. Res Mol Med 2016; 4: 18-23.

13. Chekhun VF, Zalutskii IV, Naleskina LA, et al. Modifying effects of lactoferrin in vitro on molecular phenotype of human breast cancer cells. Exp Oncol 2015; 37: 181-6.

14. Koblyakov AV, Kobliakov VA, Antoshina EE, et al. The inhibitory effect of human lactoferrin (neolactoferrin) on the growth of transplantable cervical tumors in mice. Vopr Onkol 2012; 58: 668-73 (in Russian).

15. Tsuda H, Kozu T, Iinuma $G$, et al. Cancer prevention by bovine lactoferrin: from animal studies to human trial. Biometals 2010; 23: 399-409.

16. Lukashevich VS, Budzevich AI, Semak IV, et al. Production of recombinant human lactoferrin from the milk of goat-producers and its physiological effects. Proc Nat Acad Sci Belarus 2016; 60: 72-81 (in Russian).

17. Somasundaram R, Villanueva J, Herlyn M. Intratumoral heterogeneity as a therapy resistance mechanism: role of melanoma subpopulations. Adv Pharmacol 2012; 65: 33559.
18. Malek AV, Bershtein LM. MicroRNA; sex steroids, hormonal carcinogenesis, hormonal sensitivity of tumor tissue. Adv Molec Oncol 2015; 2: 4-12 (in Russian).

19. Fabris L, Ceder Y, Chinnaiyan AM, et al. The potential of microRNAs as prostate cancer biomarkers. Eur Urol 2016; 70: $312-22$.

20. Paterni I, Granchi C, Katzenellenbogen JA, et al. Estrogen receptors alpha $(\mathrm{ER} \alpha)$ and beta $(\mathrm{ER} \beta)$ : subtype-selective ligands and clinical potential. Steroids 2014; 90: 13-29.

21. Brennen WN, John TI. Cellular origin of androgen receptor pathway-independent prostate cancer and implications for therapy. Cancer Cell 2017; 32: 399-401.

22. Stone KR, Mickey DD, Wunderli H, et al. Isolation of a human prostate carcinoma cell line (DU 145). Int J Cancer 1978; 21: 274-81.

23. Horoszewicz JS, Leong SS, Kawinski E, et al. LNCaP model of human prostatic carcinoma. Cancer Res 1983; 43: $1809-18$.

24. Sha J, Li J, Wang W, et al. Curcumin induces G0/G1 arrest and apoptosis in hormone independent prostate cancer DU- 145 cells by down regulating Notch signaling. Biomed Pharmacother 2016; 84: 177-84.

25. Linja MJ, Savinainen KJ, Saramäki OR, et al. Amplification and overexpression of androgen receptor gene in hormonerefractory prostate cancer. Cancer Res 2001; 61: 3550-55.

26. Ueda M, Shimizu T, Mabuchi M, et al. Novel metabolically stable PCA-1/ALKBH3 inhibitor has potent antiproliferative effects on DU145 cells in vivo. Anticancer Res 2018; 38: 211-18.

27. van Bokhoven A, Varella-Garcia M, Korch C, et al. Molecular characterization of human prostate carcinoma cell lines. Prostate 2003; 57: 205-25.

28. Chen T, Wang LH, Farrar WL. Interleukin 6 activates androgen receptor-mediated gene expression through a signal transducer and activator of transcription 3-dependent pathway in LNCaP prostate cancer cells. Cancer Res 2000; 60: 2132-35.

29. Guo Z, Yang X, Sun F, et al. A novel androgen receptor splice variant is up-regulated during prostate cancer progression and promotes androgen depletion-resistant growth. Cancer Res 2009; 69: 2305-13.

30. Danforth DN, Sgagias MK. Interleukin- $1 \alpha$ and interleukin-6 act additively to inhibit growth of MCF-7 breast cancer cells in vitro. Cancer Res 1993; 53: 1538-45.

31. Ha NH, Nair VS, Reddy DN, et al. Lactoferrin-endothelin-1 axis contributes to the development and invasiveness of triplenegative breast cancer phenotypes. Cancer Res 2011; 71: 7259-69.

32. Liao X, LuH, WangDL, et al. Estrogen receptor $\alpha$ mediates proliferation of breast cancer MCF-7 cells via a p21/ PCNA/E2F1-dependent pathway. FEBS J 2014; 281: 927-42.

33. Xing-Hua Liao, Da-Lin Lu, Nan Wang, et al. Human delta-lactoferrin is a transcription factor that enhances Skp1 (S-phase kinase-associated protein) gene expression. FEBS J 2007; 274: 2038-53.

34. Dickson RB, Huff KK, Spencer EM, et al. Induction of epidermal growth factor-related polypeptides by 17-bestradiol in MCF-7 human breast cancer cells. Endocrinology 1986; 118: 138-42.

35. Yang C, Chen L, Li C, et al. Cyclin D1 enhances the response to estrogen and progesterone by regulating progesterone receptor expression. Mol Cell Biol 2010; 30: 3111-25.

36. Helguero LA, Lindberg $K$, Gardmo $C$, et al. Different roles of estrogen receptors $\alpha$ and $\beta$ in the regulation of E-cadherin protein levels in a mouse mammary epithelial cell line. Cancer Res 2008; 68: 8695-04. 